\title{
Flow Diverter Devices for the Treatment of Unruptured Vertebral Artery Dissecting Aneurysm
}

\author{
Chang Hyeun Kim, ${ }^{1,2,3}$ Chi Hyung Lee, ${ }^{1,2,3}$ Young Ha Kim, ${ }^{1,2,3}$ Soon Ki Sung, ${ }^{1,2,3}$ Dong Wuk Son, ${ }^{1,2,3}$ Sang Weon Lee, ${ }^{1,2,3}$ \\ Geun Sung Song ${ }^{1,2,3}$ \\ Department of Neurosurgery, Pusan National University Yangsan Hospital, Yangsan, Korea \\ Research Institute for Convergence of Biomedical Science and Technology, ${ }^{2}$ Pusan National University Yangsan Hospital, Yangsan, Korea \\ Department of Neurosurgery, ${ }^{3}$ School of Medicine, Pusan National University, Yangsan, Korea
}

Objective : Vertebral artery dissecting aneurysm (VADA) is a very rare subtype of intracranial aneurysms; when ruptured, it is associated with significantly high rates of morbidity and mortality. Despite several discussions and debates, the optimal treatment for VADA has not yet been established. In the last 10 years, flow diverter devices (FDD) have emerged as a challenging and new treatment method, and various clinical and radiological results have been reported about their safety and effectiveness. The aim of our study was to evaluate the clinical and radiological results with the use of FDD in the treatment of unruptured VADA.

Methods : We retrospectively evaluated the data of all patients with unruptured VADA treated with FDD between January 2018 and February 2021 at our hybrid operating room. Nine patients with unruptured VADA, deemed hemodynamically unstable, were treated with FDD. Among other parameters, the technical feasibility of the procedure, procedure-related complications, angiographic results, and clinical outcomes were evaluated.

Results : Successful FDD deployment was achieved in all cases, and the immediate follow-up angiography showed intraaneurysmal contrast stasis with parent artery preservation. A temporary episode of facial numbness and palsy was noted in one patient; however, the symptoms had completely disappeared when followed up at the outpatient clinic 2 weeks after the procedure. The 3-6 months follow-up angiography $(\mathrm{n}=9)$ demonstrated complete/near-complete obliteration of the aneurysm in seven patients, and partial obliteration and segmental occlusion in one patient each. In the patient who achieved only partial obliteration, there was a sac $13 \mathrm{~mm}$ in size, and there was no change in the 1-year follow-up angiography. In the patient with segmental occlusion, the cause could not be determined. The clinical outcome was modified Rankin Scale 0 in all patients.

Conclusion : Our preliminary study using FDD to treat hemodynamically unstable unruptured VADA showed that FDD is safe and effective. Our study has limitations in that the number of cases is small, and it is not a prospective study. However, we believe that the study contributes to evidence regarding the safety and effectiveness of FDD in the treatment of unruptured VADA.

Key Words : Vertebral artery · Aneurysm, dissecting · Intracranial aneurysm · Endovascular procedures.

- Received : July 17, 2021 •Revised : August 20, 2021 •Accepted : August 27, 2021

- Address for reprints : Sang Weon Lee

Department of Neurosurgery, Pusan National University Yangsan Hospital, 20 Geumo-ro, Mulgeum-eup, Yangsan 50612, Korea

Tel : +82-55-360-2126, Fax : +82-55-360-2156, E-mail : sangweonlee@pusan.ac.kr, ORCID : https://orcid.org/0000-0002-3199-7072

This is an Open Access article distributed under the terms of the Creative Commons Attribution Non-Commercial License (http://creativecommons.org/licenses/by-nc/4.0) which permits unrestricted non-commercial use, distribution, and reproduction in any medium, provided the original work is properly cited. 


\section{INTRODUCTION}

Vertebral artery dissecting aneurysm (VADA) is a very rare subtype of intracranial aneurysm, which when ruptured, is associated with significant rates of morbidity and mortality. Although there have been many discussions and reports about VADAs, the optimal treatment method has not yet been clearly established. In the case of ruptured VADAs, a reconstruction method including stent coiling or multiple stents, or a deconstruction method such as parent artery trapping is performed according to the characteristics of the case. However, for the treatment of unruptured VADAs, conservative treatment using anticoagulation therapy is the first line of treatment; nevertheless, depending on the status, including the size of the dissecting segment and the change in shape or progression of related symptoms, endovascular treatment is also actively considered $^{25)}$.

The treatment is determined according to the dominance of the parent artery and the inclusion of posterior inferior cerebellar artery (PICA) or various branches in the dissecting segment, and is not different from the treatment for ruptured VADAs. In recent times, with the development of endovascular devices, treatment of such cases using flow diverter devices (FDD) such as Pipeline Embolization Device (PED; Medtronic Inc., Minneapolis, MN, USA), Flow Redirection Endoluminal Device (FRED; Microvention, Aliso Viejo, CA, USA), and Surpass Flow-Diverter (Surpass; Stryker Neurovascular, Fremont, CA, USA) has been reported. However, such reports were individual cases with successful treatment outcomes ${ }^{19,27,28)}$. The purpose of this study was to determine the radiological and clinical results of consecutive cases treated with FDD for unruptured VADA considered to be hemodynamically unstable lesions.

\section{MATERIALS AND METHODS}

This retrospective study was approved by the Institutional Review Board of Pusan National University Yangsan Hospital (IRB 05-2021-177).

\section{Study population demographics and characteristics}

We retrospectively included all patients treated with the FDD at our hybrid operating room between January 2018 and February 2021 for clinically and angiographic confirmed un- ruptured VADA. Our institution defined an aneurysm with fusiform change and irregular shape in the vertebral artery (VA), accompanied by sudden posterior neck pain, as a dissecting aneurysm. And in short term follow-up vessel wall magnetic resonance (MR) image, if an intimal flap, mural hematoma, or thrombus is identified, we confirmed the lesion as a dissecting aneurysm. In addition, hemodynamically unstable lesions to be treated as follows; a history of subarachnoid hemorrhage (SAH), increased dissecting size on follow-up, increased size of thrombus, and sustained contrast stagnation in the dissecting segments were considered as indications for treatment. We did not use FDD for VAD with stenosis or pear-string sign. In this case, there is a possibility that occlusion may occur at the stenosis site during the procedure.

Therapeutic options such as parent artery occlusion, stentassisted coiling, and multiple stents were discussed between the patients and our vascular team; the benefits and risks for all treatment options as well as the FDD were discussed.

\section{Endovascular procedures}

Diagnostic and endovascular procedures were performed using the Artis Zeego robotic C-arm monoplane digital subtraction angiography (DSA) system (Siemens Healthcare, Forchheim, Germany) in the hybrid operating room. Except for one patient, all patients underwent treatment under general anesthesia. An 8-Fr femoral sheath was placed in the right femoral artery. DSA and 3D rotational angiography were performed, and these images were used to determine the best working angle and measure the size of dissecting segment and diameter of the parent artery. A 6-Fr Shuttle (Cook, Bloomington, IN, USA) guiding catheter with 5-Fr Sofia (Microvention) intermediate catheter was placed in the VA. Using a coaxial system, a Headway 27 or 21 microcatheter (Microvention) was navigated over a Synchro-14 (Boston Scientific, Natick, MA, USA) microwire in the target artery, beyond the dissecting segment. The FDD was navigated and deployed across the dissecting segment using a standard push and pull technique in all cases. After deployment of the FFD, dyna-CT (Siemens Healthcare) was performed to identify the FFD wall apposition. At the end of this process, a DSA image was taken after 15 minutes to confirm delayed thrombus formation.

Determination of the size and length of FDD is highly related to the success or failure of the treatment. Therefore, we decided the appropriated size and length as follows. The size of 
the FDD was determined using the average value of the proximal and distal portion of the normal vessel to be covered by the FDD, and the length was determined with a margin of 5 to $10 \mathrm{~mm}$.

For the successful deployment of FDD during the procedure, two part were considered the most. First, the distal part of FDD should be spread in the shape of a wine glass, and then placed at the appropriated distal portion. The next important thing is to deploy FDD uniformly. For this, it is important to deploy FDD while maintaining proper tension on the intermediated catheter and mcrocatheter.

\section{Antiplatelet medication}

Patients were administered aspirin (100 mg) and clopidogrel (75 mg) daily for at least 7 days before the elective procedure. P2Y12 reaction units (PRU) were analyzed using the Verify Now assay prior to the procedure, and patients with values greater than 230 were regarded as clopidogrel non-responders. In such patients, prasugrel was administered immediately before the procedure, and clopidogrel was replaced with prasugrel after the procedure. During the procedure, 3000 IU of heparin was administered (depending on the patient's body weight, $50 \mathrm{IU} / \mathrm{Kg}$ ). If the procedural duration exceeded 1 hour, an additional $1000 \mathrm{IU}$ of heparin were administered per hour.

All procedures were performed under general anesthesia except in one patient who had a high risk of developing respiratory failure during general anesthesia due to Swyer James syndrome. All procedures were performed via femoral artery access with systemic heparinization. The flush system contained $5000 \mathrm{IU}$ of heparin per liter.

\section{Assessment and follow-up}

Clinical data, neurological examination at baseline, and outcomes based on modified Rankin Scale (mRS) scores at discharge and at 2 weeks and 3, 6, 9, 12-month follow-up were evaluated.

Follow-up angiography was performed after device placement at during 3-6 months follow-up. Follow-up imaging was evaluated for patency of the parent vessel and branching artery; obliteration of the aneurysm, and contrast stagnation was graded according to the grading scales for occlusion of the aneurysm after FDD treatment ${ }^{9,11,24)}$. If the result on the first angiography appeared good (aneurysm obliteration grades 3 and 4), the course was observed after 6 months with MR ves- sel wall images. In cases with poor results (aneurysm obliteration grades 1 and 2), conventional angiography was performed once more at 12 months.

In addition, dyna-CT was performed after placement to ascertain the apposition of the FDD with the parent vessel wall.

\section{RESULTS}

There were nine patients (seven females and four males), and the mean age was 54 years (range, 32-74) (Table 1). The exact location of the lesion was determined by diagnostic angiography and MR vessel wall images. Eight patients were V4 segment and one patient was V3 segment. In seven of these patients were PICA involving dissecting segment. The dominancy of the left and right side was compared through diagnostic angiography, and if the size was twice as thick, it was considered as a dominant. The lesion was in the dominant VA in two patients, in the non-dominant artery in two patients, and in five patients, the left and right dominance were not clear.

On admission, five patients had a lesion-related occipital headache, but four had no related symptoms. Therefore, the mRS score of five patients was 1 point.

Endovascular access and treatment were successful in all nine cases. All devices were successfully placed over the dissecting segment, providing complete coverage and demonstrating contrast stagnation in the dissecting segment on immediate angiography and 15 minutes delayed angiography. There were no peri-procedural or immediate post-procedural complications, except in one patient (case No. 6). The patient complained of mild facial palsy and numbness on the day after the procedure, and a small infarction was found in the medulla on diffusion-weighted magnetic resonance imaging (MRI) (Fig. 1C). The patient's symptoms completely disappeared the next day, and he was discharged on the third day. All patients were discharged following the 3 days follow-up after the procedure. At the time of discharge, none of the patients complained of related symptoms or signs. None of the patients complained of discomfort during the outpatient clinical follow-up. All the patients who had a headache reported improvement in headache.

The data of follow-up conventional angiography at 3-6 months was available for all patients (Table 2). Complete/nearcomplete obliteration (grading scale 3 and 4) was seen seven 


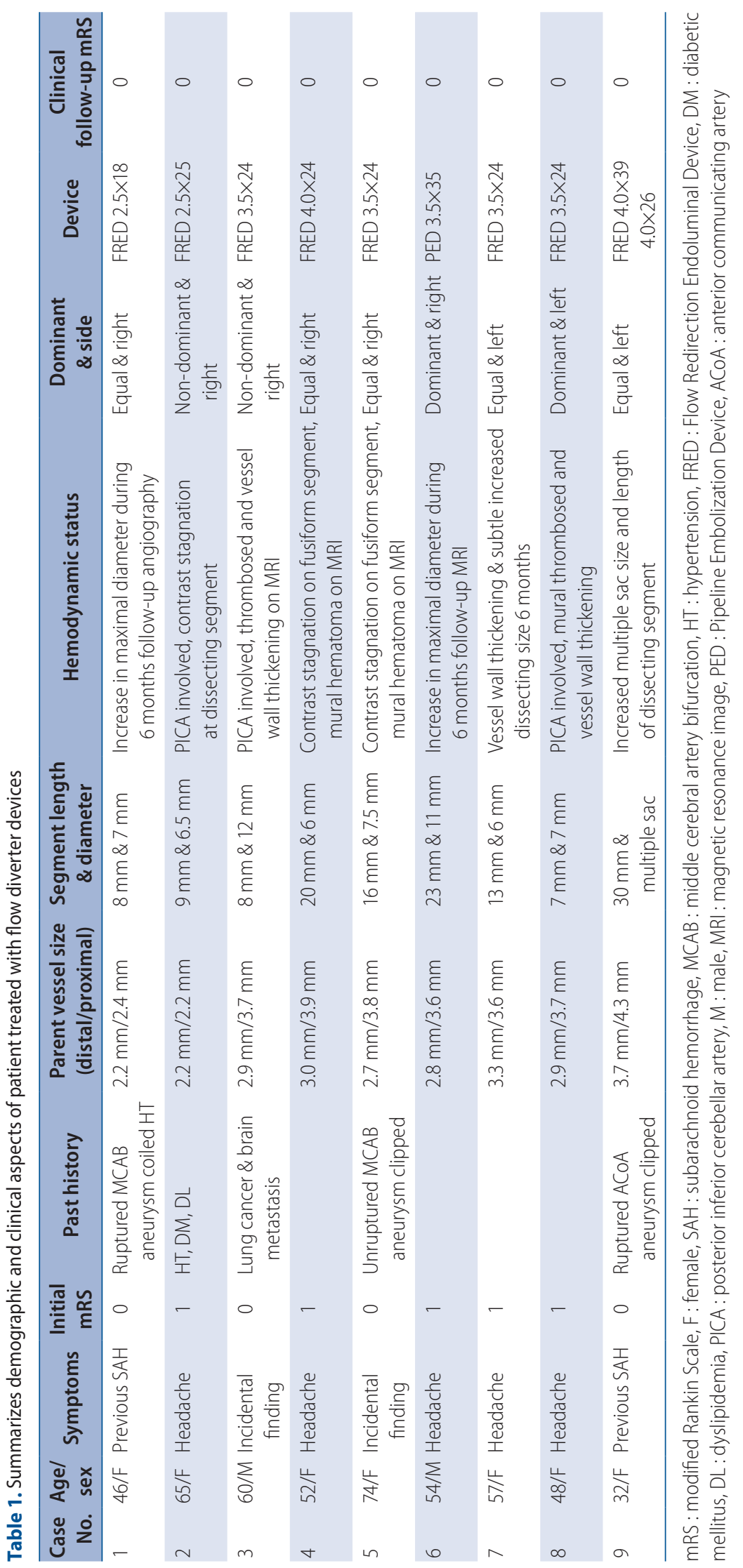


patients. In one patient, the maximal aneurysm size, including the thrombus was decreased, but partial obliteration state. At the 12-month follow-up angiography, the results were not different from those of the first angiography. In one patient (case No. 6, Fig. 1), the first conventional angiography revealed occlusion of the dissecting segment in which the FDD was deployed.

All nine patients were able to confirm their clinical status as planned, at the outpatient clinic. Six months after the procedure, the antiplatelet medication was changed from dual to
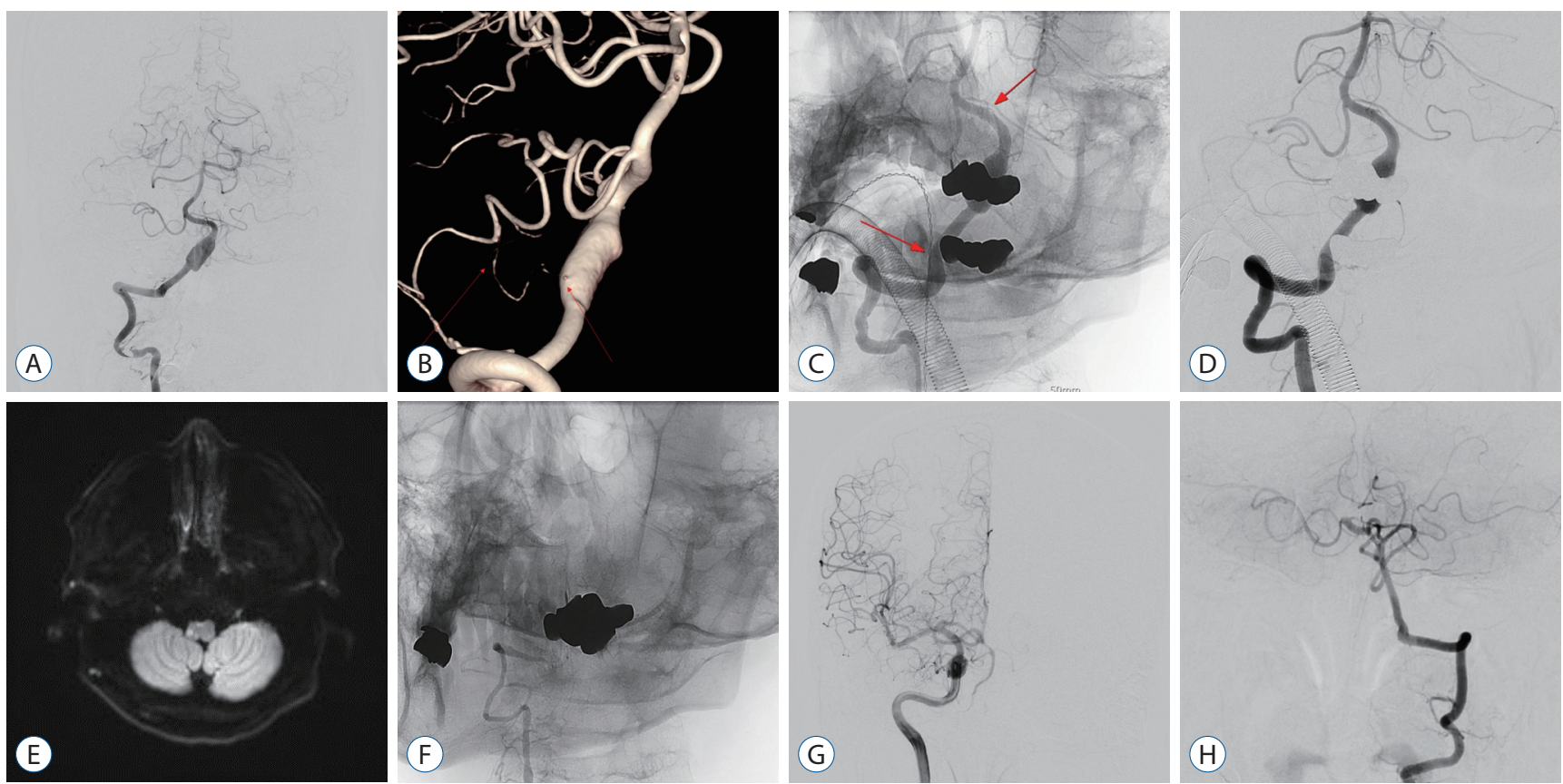

Fig. 1. Case No. 6. A : Digital subtraction angiography (DSA) shows a vertebral artery dissecting aneurysm ( $23 \times 11 \mathrm{~mm})$. B : A small posterior inferior cerebellar artery originating at dissecting segment, but a connection with the anterior inferior cerebellar artery is observed. C : A Pipeline embolization device (PED) was appropriately deployed to adequately cover the dissecting segment without crossing the contralateral vertebrovasilar junction. The arrows indicate the distal/proximal tip position of the PED. D : DSA follow-up 15 minutes after the procedure shows no abnormalities. E : A diffusion weighted image performed the day after the procedure shows a small infarction at the medulla oblongata. F : Three months follow-up DSA shows that the lesion where the PED was deployed is completely occluded. The size of the vertebral artery is also reduced due to the occluded lesion. $\mathrm{G}$ and $\mathrm{H}$ : Blood flow through the contralateral vertebral artery and retrograde collateral flow through the posterior communicating artery fills the occluded right vertebral artery territory.

Table 2. Summary of angiographic outcomes

\begin{tabular}{|c|c|c|c|c|c|c|c|c|c|}
\hline \multirow{2}{*}{$\begin{array}{c}\text { Case } \\
\text { No. }\end{array}$} & \multicolumn{3}{|c|}{ Immediate angiography } & \multicolumn{3}{|c|}{ 3-6 months angiography follow-up } & \multicolumn{3}{|c|}{12 months angiography follow-up } \\
\hline & $\begin{array}{c}\text { Grunwald } \\
\text { et al. }{ }^{9}\end{array}$ & $\begin{array}{l}\text { Kamran } \\
\text { et al. }{ }^{11)}\end{array}$ & $\begin{array}{l}\text { O'Kelly } \\
\text { et al. }{ }^{24)}\end{array}$ & $\begin{array}{c}\text { Grunwald } \\
\text { et al.9) }\end{array}$ & $\begin{array}{l}\text { Kamran } \\
\text { et al.. }\end{array}$ & $\begin{array}{l}\text { O'Kelly } \\
\text { et al. }{ }^{24)}\end{array}$ & $\begin{array}{c}\text { Grunwald } \\
\text { et al. }{ }^{9)}\end{array}$ & $\begin{array}{l}\text { Kamran } \\
\text { et al. }{ }^{11)}\end{array}$ & $\begin{array}{l}\text { O'Kelly } \\
\text { et al. }{ }^{24}\end{array}$ \\
\hline 1 & $O c$ & $O A$ & $A 3$ & 4 & $4 \mathrm{~A}$ & D & 4 & $4 \mathrm{~A}$ & D \\
\hline 2 & $\mathrm{Ob}$ & $O A$ & $A 2$ & $3 c$ & $3 A$ & C & 4 & $4 \mathrm{~A}$ & D \\
\hline 3 & Oc & $O A$ & A3 & $2 c$ & $2 \mathrm{~A}$ & B3 & $2 c$ & $2 \mathrm{~A}$ & B3 \\
\hline 4 & Oc & $O A$ & A3 & $3 b$ & $3 \mathrm{~A}$ & C2 & & & \\
\hline 5 & Oc & $O A$ & A3 & $3 b$ & $3 \mathrm{~A}$ & $C 2$ & $3 b$ & $3 \mathrm{~A}$ & $\mathrm{C} 2$ \\
\hline 6 & $\mathrm{Ob}$ & $\mathrm{OA}$ & A2 & \multicolumn{3}{|c|}{ Segmental occlusion } & & & \\
\hline 7 & Ob & $O A$ & A2 & 4 & $4 \mathrm{~A}$ & $\mathrm{D}$ & & & \\
\hline 8 & $a b$ & $O A$ & A2 & 4 & $4 \mathrm{~A}$ & $D$ & & & \\
\hline 9 & Oc & $O A$ & A3 & 4 & $4 \mathrm{~A}$ & $\mathrm{D}$ & & & \\
\hline
\end{tabular}


monotherapy.

\section{Illustration case 1 (case No. 1)}

A 46-year-old female patient complained of sudden onset headache and was admitted to the emergency room. MRI and magnetic resonance angiography (MRA) showed a ruptured right middle cerebral artery aneurysm and unruptured right V4 dissecting aneurysm. Coil embolization was performed for treatment of the ruptured aneurysm, and conventional angiography performed 6 months later revealed mild enlargement of the V4 dissecting aneurysm. Treatment was decided considering the history of SAH. FRED was successfully deployed at the site of the lesion. At the follow-up angiography after 6 months, scanty contrast inflow was observed, and at the follow-up angiography after 12 months, complete obliteration of the aneurysm was confirmed (Fig. 2).

\section{Illustration case 2 (case No. 3)}

A 60-year-old male patient was referred to the neurosurgery unit following the detection of an aneurysm on a brain MRI performed for evaluation of lung cancer metastasis. PICA originated V4 dissecting aneurysm was found, and part of the aneurysm was filled with thrombus. Because of the poor cardiopulmonary function, general anesthesia could not be administered, and treatment was planned using FDD, which had a short procedural duration. The procedure was performed under mild sedation with pain control and was successful. Since retention of the contrast stagnation was clearly seen, immediately after the procedure, a good result was expected. However, in the angiography at 3 and 12 months, the contrast stagnation decreased compared to that in the immediate postoperative state, but the aneurysm was only partially occluded (Fig. 3). Considering the poor life expectancy anticipated due to lung cancer no additional treatment was provided.
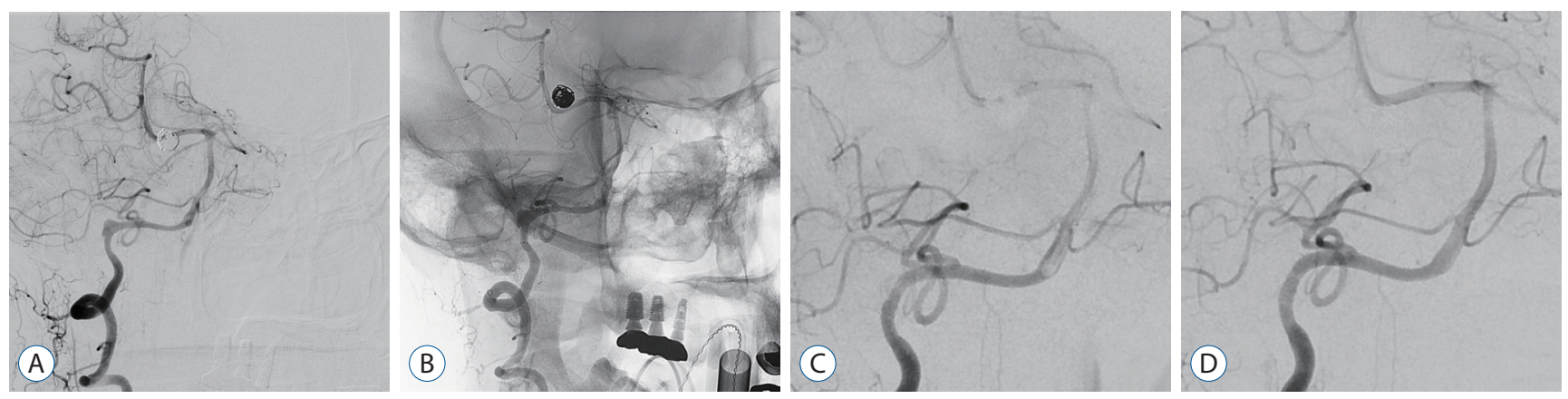

Fig. 2. Case No 1. A : Digital subtraction angiography (DSA) showing a vertebral artery dissecting aneurysm ( $8 \times 6 \mathrm{~mm})$. B : Flow Redirection Endoluminal Device (FRED; $2.5 \times 18$ ) was deployed across the aneurysm neck. C : Six-month follow-up DSA shows marked reduction in the size of the aneurysm. However, until the venous phase, the contrast stagnation is retained in the part of the aneurysm. D : Twelve-month follow-up DSA demonstrates a completely remodeled normal vertebral artery.
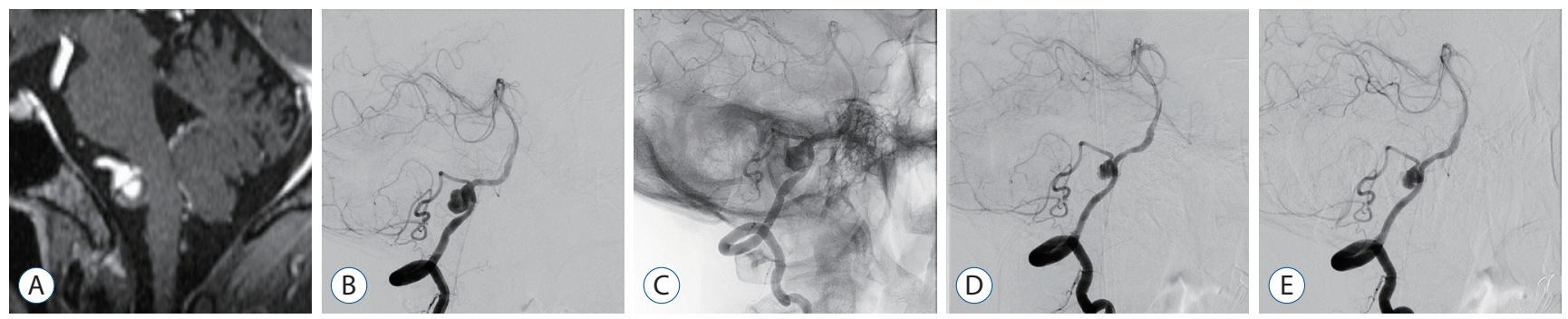

Fig. 3. Case No. 3. A : Contrast magnetic resonance imaging to confirm brain metastasis of lung cancer shows a thrombosed aneurysm. B : In digital subtraction angiography (DSA), a dissecting aneurysm is observed with a large sac involving the origin of the posterior inferior cerebellar artery. $C$ : Flow Redirection Endoluminal Device (FRED) was deployed without crossing the contralateral vertebrobasilar junction and including across the aneurysm neck. D : The size of the aneurysm was reduced in DSA at 3-month follow-up DSA. However, it has reduced by more than 50\%, and a large amount of contrast agent still fills the aneurysm. E: Twelve-month follow-up DSA, shows no difference compared to the previous exam. 


\section{Illustration case 3 (case No. 6)}

A 54-year-old male patient visited the outpatient clinic due to an abnormal finding on the MRAs. He had the first episode of headache 6 months ago, and a dissecting aneurysm on the right V4 segment was seen on the MRI performed at a local hospital. However, the local hospital could not diagnose the lesion. Six months later, the patient revisited the hospital due to a mild headache, and MRI and MRA were performed again. The lesion was discovered at that time, and the size of the dissection segment had increased; hence, he was referred to our hospital.

It was found that a small PICA originated in the dissecting segment, but there was a connection with the anterior inferior cerebellar artery. Considering that the patients were young and the lesion involved the dominant VA, it was decided to use FDD for the treatment. The procedure was performed successfully, and after 15 minutes, no remarkable finding was seen on the DSA. Immediately after the procedure, the patient had no abnormal symptoms. However, on the next day, the patient complained of mild facial palsy and facial numbness. We performed diffusion-weighted MRI and confirmed a small infarction at the medulla oblongata. Fortunately, on the next day the symptoms had completely disappeared. The patient's PRU was 209, which was within the therapeutic zone, but we used prasugrel instead of clopidogrel. At the scheduled outpatient clinic visit, the patient reported that the headache had improved and there were no symptoms.

On the conventional angiography performed 3 months later, it was confirmed that the entire parent artery where the FDD was deployed was occluded. Fortunately, the retrograde flow through the fetal-type posterior communicating artery (PCoA) provided adequate blood supply to the basilar artery and cerebellar arteries (Fig. 1).

\section{DISCUSSION}

VADA is a very rare disease; however, due to the high morbidity and mortality associated with it, careful management with neurosurgery is necessary. Since MRI was introduced as a diagnostic modality, unruptured VADA has been diagnosed more frequently ${ }^{21}$. VADA alters the shape of the parent artery leading to narrowing, widening, occlusion, or pseudo-aneurysm formation. As a result, it might cause sub-occipital head- ache, cerebral infarction, or SAH. In particular, in patients presenting with $\mathrm{SAH}$, a poor outcome is predicted due to the high rate of re-bleeding ${ }^{20,30)}$. Therefore, it is important for neurosurgeons to analyze the risk factors for rupture and decide on an appropriate treatment for unruptured VADA.

Anticoagulants are preferred for the conservative management of hemodynamic stable VADA ${ }^{25)}$. However, there is a study showing that there is no difference in efficacy of antiplatelet and anticoagulant medications at preventing stroke and death in patients with symptomatic carotid and vertebral artery dissection ${ }^{2}$. Since we are more familiar with antiplatelet drugs for 1 year in VADA patients who needed conservative care.

Treatment for unruptured VADA is debatable, and there are no established guidelines about the optimal treatment. Kobayashi et al. ${ }^{14)}$ recommended treatment if the dissection segment length was more than $10 \mathrm{~mm}$ or if symptoms such as associated pain or mass effect were present. Nakagawa et al. ${ }^{22)}$ reported that treatment is necessary if an increase in the size of the dissecting segment is detected within a short period of time. Conversely, Kim and $\mathrm{Lim}^{13)}$ reported that spontaneous healing of unruptured VADA is more likely in females, nonsmokers, those with no involvement of the posterior-inferior cerebellar artery, and less luminal irregularity/steno-occlusion. Therefore, unruptured VADA should be treated considering the hemodynamic status, and the treatment should be carefully decided based on each individual case.

The well-known treatment methods include reconstructive and deconstructive treatment. The deconstructive treatment method completely occludes the dissecting segment using an endovascular or surgical approach. This method is considered a stable treatment in that there is no recurrence of the lesion ${ }^{12)}$. However, in the case of dominant VA, there is a risk of ischemic symptoms due to the occlusion of a small branching artery and hemodynamic changes. In addition, there is a disadvantage that bypass needs to be considered for lesions involving PICA. Reconstructive treatment maintains the flow of the dissecting segment ${ }^{5,31)}$. It includes methods such as stent-assisted coil embolization, deploying a single stent, or performing multiple stenting. Nam et al. ${ }^{23)}$ reported that internal trapping is a stable and effective treatment with no recurrence in ruptured VADA. Reconstructive treatment using stent and coil requires serial DSA follow-up for the risk of recurrence, but it could be a feasible alternative for ruptured 
VADA $^{23)}$. Li et al. ${ }^{17)}$ reported that in unruptured VADA, internal trapping increases the risk of ischemia, and multiple stenting with coil embolization could reduce recurrence and occlude the aneurysm. There are reports of successful treatment using multiple stents ${ }^{18,26)}$; however, there are also reports of risks such as in-stent stenosis, thrombosis, and branch occlusion ${ }^{7,16)}$.

The use of FDDs is a relatively new and challenging endovascular treatment method that has redefined aneurysm treatment. Although there are differences in the structure and composition of each FDD, they provide high metal coverage, divert the blood inflow of the aneurysm and promote thrombus formation in the aneurysm ${ }^{15)}$. At the same time, the parent artery should be reconstructed, and the patency of major and minor side branches must be maintained. In eight of our nine cases, blood flow in the side branches and parent artery flow were maintained well, except in the one case with segmental occlusion (case No. 6).

There are several reports of successful treatment of VADA using PED. Yeung et al. ${ }^{32)}$ reported excellent clinical and angiographic outcomes of four cases of unruptured dissecting VADA treated with PED. Although this report included long-term outcomes with a mean follow-up of 22 months, the dissection segment was not long. Cohen et al. ${ }^{3)}$ reported successful treatment using PED in eight cases with ischemic cerebrovascular conditions, including three cases of VADA. The cases of VADA were successfully treated, but another case of chronic internal carotid artery dissection had segment occlusion. Kühn et al. ${ }^{15)}$, reported that a 6-month angiographic follow-up showed complete occlusion in three cases, near-complete in two cases, and partial occlusion in one out of six cases of unruptured VADA treated using PED. In addition to these reports, Corley et al. ${ }^{4)}$ reported nine cases treated with PED, of which eight had complete occlusion. Of these nine cases, five presented with $\mathrm{SAH}$, and one case presented with infarction. According to Corley et al. ${ }^{4}$, in aneurysms with saccular components larger than 10 $\mathrm{mm}$, using additional coils is recommended to promote aneurysm occlusion and reduce the risk of re-bleeding. Therefore, in our case No. 3, it is presumed that the aneurysm was not completely occluded because the saccular component was large at $13 \mathrm{~mm}$.

There are reports of successful treatment using FDD; however, there are also reports about some necessary cautions. Typically, hemorrhagic complications, including delayed or remote hemorrhage and thromboembolic events, including in-stent thrombosis, are reported. Tan et al. ${ }^{29)}$ reported that five of 74 patients $(6.8 \%)$ with PED had a thromboembolic event, and one patient (1.4\%) developed delayed intracranial hemorrhage. Moreover, 50.9\% of patients exhibited changes on post-procedural MRI diffusion-weighted imaging, and up to $14 \%$ experienced symptomatic infarctions ${ }^{29)}$. Delgado Almandoz et al. ${ }^{6}$ reported that among 48 PEDs used in 44 patients, they experienced four (8.3\%) thromboembolic events and four events $(8.3 \%)$ of hemorrhagic complications. Acute thromboembolic events might occur due to direct perforator blockage from a tine or strut of the FDD; chronic thromboembolism might occur due to excessive neo-intimal proliferation $^{4)}$. Fiorella et al. ${ }^{8)}$ reported a case wherein a patient developed very late fetal thrombosis a year after multiple PEDs with coils were placed for fusiform aneurysms of the dominant VA. The patient's contralateral VA was occluded before the procedure, and eventually, the patient died due to a large brain stem infarction ${ }^{8)}$. They also could not confirm the cause of delayed thrombosis. In our illustration case No 3, it was difficult to ascertain at what point the occlusion developed. Fortunately, the contralateral VA was patent, and bilateral PCoA was very well developed; hence, no clinical symptoms occurred.

Although there are few reports about the results of using FDD as a treatment for VADA, there are also few reports about its complications; nevertheless, there has been a regular concern about the safety of FDD use. In addition to the thromboembolic events mentioned above, there are complications related to hemorrhage. These are complications in which an aneurysm ruptured despite treatment with FDD, or intracerebral hemorrhage (ICH) occurred in the ipsilateral hemisphere where the FDD was used. Although it is a relatively early data from a retrospective study on PED among 793 patients, spontaneous rupture occurred in five patients (0.6\%), and intra-parenchymal hemorrhage occurred in 19 patients $(2.4 \%)^{10)}$. In a pipeline for uncoilable or failed aneurysms trial, 107 patients treated with pipeline, ICH was reported in five patients $(4.6 \%)^{1)}$. The exact mechanism of the hemorrhage complications has not been elucidated. However, as a possible theory, the most probable cause of ipsilateral hemispheric intraparenchyme hemorrhage is procedural embolization of some type of material-small thrombus, air bubbles, catheter coating that result in microvascular damage, transient occlusion with microinfarction, or hemorrhagic reperfusion ${ }^{1)}$. 
However, in the recently published The Pipeline Flex with SHield Technology Embolization-An International MulticEnter ObservationaL Post-Market StuDy (SHIELD), a multi-center, prospective study on improved PED, ICH did not occur and major stroke occurred in six patients $(2.9 \%)^{28)}$. Nevertheless, it needs to be noted that about half the patients (102 patients) had small aneurysms of size $7 \mathrm{~mm}$ or less, and in 47 patients (23\%) PED was used as re-treatment ${ }^{28)}$.

\section{CONCLUSION}

We reported the angiographic and clinical results of treatment with FDD in nine cases of unruptured VADA. Within 1 year after the procedure, seven cases showed complete/nearcomplete occlusion, one case with a $13 \mathrm{~mm}$ sac showed partial occlusion, and one case showed segmental occlusion. Although this is a report of only nine cases, it is valuable in that it reports the treatment outcomes of FDD for long segment VADA that was considered hemodynamic unstable. The cause of segmental occlusion in one case was unknown; however, it indicates that more caution is necessary in such cases than when FDD is used for dominant VA. Another limitation is that we used FRED more than PED, which is the most widely used FDD. However, we believe that our study contributes to the evidence regarding the safety and effectiveness of FDD in the treatment of unruptured VADA. We consider the FDD to be a feasible treatment option for unruptured VADA.

\section{CONFLICTS OF INTEREST}

Dong Wuk Son has been editorial board of JKNS since November 2017. He was not involved in the review process of this original article. No potential conf lict of interest relevant to this article was reported.

\section{INFORMED CONSENT}

This type of study does not require informed consent.

\section{AUTHOR CONTRIBUTIONS}

\author{
Conceptualization : SWL, CHK \\ Data curation : CHL, YHK \\ Formal analysis: CHK, SKS \\ Funding acquisition : SWL \\ Methodology : DWS, GSS \\ Project administration : SWL, CHK \\ Visualization : CHK \\ Writing - original draft : $\mathrm{CHK}$ \\ Writing - review \& editing: SWL, YHK
}

\section{ORCID}

Chang Hyeun Kim https://orcid.org/0000-0001-6128-456X

Chi Hyung Lee https://orcid.org/0000-0001-6323-3643

Young Ha Kim https://orcid.org/0000-0003-0477-3169

Soon Ki Sung https://orcid.org/0000-0001-7138-9621

Dong Wuk Son https://orcid.org/0000-0002-9154-1923

Sang Weon Lee https://orcid.org/0000-0002-3199-7072

Geun Sung Song https://orcid.org/0000-0002-8273-7596

\section{- Acknowledgements}

This work was supported by a 2-Year Research Grant of Pusan National University.

\section{References}

1. Becske $T$, Kallmes DF, Saatci I, McDougall CG, Szikora I, Lanzino G, et al. : Pipeline for uncoilable or failed aneurysms: results from a multicenter clinical trial. Radiology $267:$ 858-868, 2013

2. CADISS trial investigators, Markus HS, Hayter E, Levi C, Feldman A, Venables $G$, et al. : Antiplatelet treatment compared with anticoagulation treatment for cervical artery dissection (CADISS): a randomised trial. Lancet Neurol 14 : 361-367, 2015

3. Cohen JE, Gomori JM, Rajz G, Itshayek E, Eichel R, Leker RR : Urgent off-label use of the pipeline flow diverter stent in selected ischemic cerebrovascular conditions: thrombotic segments and tortuous arteries. J Neurointerv Surg 7 : 671-675, 2015

4. Corley JA, Zomorodi A, Gonzalez LF : Treatment of dissecting distal vertebral artery (V4) aneurysms with flow diverters. Oper Neurosurg (Hagerstown) 15 : 1-9, 2018

5. Dabus $G$, Lin $E$, Linfante I: Endovascular treatment of fusiform intracranial vertebral artery aneurysms using reconstructive techniques. J Neu- 
rointerv Surg 6 : 589-594, 2014

6. Delgado Almandoz JE, Crandall BM, Scholz JM, Fease JL, Anderson RE, Kadkhodayan $Y$, et al. : Pre-procedure P2Y12 reaction units value predicts perioperative thromboembolic and hemorrhagic complications in patients with cerebral aneurysms treated with the pipeline embolization device. J Neurointerv Surg 5 Suppl 3 : iii3-iii10, 2013

7. Fiorella D, Albuquerque FC, Deshmukh VR, Woo HH, Rasmussen PA, Masaryk TJ, et al. : Endovascular reconstruction with the Neuroform stent as monotherapy for the treatment of uncoilable intradural pseudoaneurysms. Neurosurgery 59 : 291-300; discussion 291-300, 2006

8. Fiorella D, Hsu D, Woo HH, Tarr RW, Nelson PK : Very late thrombosis of a pipeline embolization device construct: case report. Neurosurgery 67(3 Suppl Operative) : onsE313-onsE314; discussion onsE314, 2010

9. Grunwald IQ, Kamran M, Corkill RA, Kühn AL, Choi IS, Turnbull S, et al. : Simple measurement of aneurysm residual after treatment: the SMART scale for evaluation of intracranial aneurysms treated with flow diverters. Acta Neurochir (Wien) 154 : 21-26; discussion 26, 2012

10. Kallmes DF, Hanel R, Lopes D, Boccardi E, Bonafé A, Cekirge S, et al. : International retrospective study of the pipeline embolization device: a multicenter aneurysm treatment study. AJNR Am J Neuroradiol 36 : 108-115, 2015

11. Kamran M, Yarnold J, Grunwald IQ, Byrne JV : Assessment of angiographic outcomes after flow diversion treatment of intracranial aneurysms: a new grading schema. Neuroradiology 53 : 501-508, 2011

12. Kashiwazaki D, Ushikoshi S, Asano T, Kuroda S, Houkin K : Long-term clinical and radiological results of endovascular internal trapping in vertebral artery dissection. Neuroradiology 55 : 201-206, 2013

13. Kim MK, Lim YC : Conservative management of unruptured spontaneous intracranial vertebral artery dissection. World Neurosurg 126 : e402-e409, 2019

14. Kobayashi N, Murayama Y, Yuki I, Ishibashi T, Ebara M, Arakawa H, et al. : Natural course of dissecting vertebrobasilar artery aneurysms without stroke. AJNR Am J Neuroradiol 35 : 1371-1375, 2014

15. Kühn AL, Kan P, Massari F, Lozano JD, Hou SY, Howk M, et al. : Endovascular reconstruction of unruptured intradural vertebral artery dissecting aneurysms with the pipeline embolization device. J Neurointerv Surg 8 : 1048-1051, 2016

16. Levy El, Boulos AS, Bendok BR, Kim SH, Qureshi Al, Guterman LR, et al. : Brainstem infarction after delayed thrombosis of a stented vertebral artery fusiform aneurysm: case report. Neurosurgery 51 : 1280-1284; discussion 1284-1285, 2002

17. Li H, Li XF, Zhang X, He XY, Duan CZ, Liu YC : Treatment of unruptured vertebral dissecting aneurysms: internal trapping or stent-assisted coiling. Int J Neurosci 126 : 243-248, 2016

18. Mehta B, Burke T, Kole M, Bydon A, Seyfried D, Malik G : Stent-withina-stent technique for the treatment of dissecting vertebral artery aneurysms. AJNR Am J Neuroradiol 24 : 1814-1818, 2003

19. Meyers PM, Coon AL, Kan PT, Wakhloo AK, Hanel RA : SCENT trial. Stroke 50 : 1473-1479, 2019
20. Mizutani T, Aruga T, Kirino T, Miki Y, Saito I, Tsuchida T : Recurrent subarachnoid hemorrhage from untreated ruptured vertebrobasilar dissecting aneurysms. Neurosurgery 36 : 905-911; discussion 912-913, 1995

21. Naito I, Iwai T, Sasaki T : Management of intracranial vertebral artery dissections initially presenting without subarachnoid hemorrhage. Neurosurgery 51 : 930-937; discussion 937-938, 2002

22. Nakagawa K, Touho H, Morisako T, Osaka Y, Tatsuzawa K, Nakae H, et al. : Long-term follow-up study of unruptured vertebral artery dissection: clinical outcomes and serial angiographic findings. J Neurosurg 93 : $19-25,2000$

23. Nam KH, Ko JK, Cha SH, Choi CH, Lee TH, Lee II : Endovascular treatment of acute intracranial vertebral artery dissection: long-term followup results of internal trapping and reconstructive treatment using coils and stents. J Neurointerv Surg $7:$ 829-834, 2015

24. O'Kelly CJ, Krings T, Fiorella D, Marotta TR : A novel grading scale for the angiographic assessment of intracranial aneurysms treated using flow diverting stents. Interv Neuroradiol 16 : 133-137, 2010

25. Park KW, Park JS, Hwang SC, Im SB, Shin WH, Kim BT : Vertebral artery dissection: natural history, clinical features and therapeutic considerations. J Korean Neurosurg Soc 44 : 109-115, 2008

26. Park SI, Kim BM, Kim DI, Shin YS, Suh SH, Chung EC, et al. : Clinical and angiographic follow-up of stent-only therapy for acute intracranial vertebrobasilar dissecting aneurysms. AJNR Am J Neuroradiol 30 : 13511356, 2009

27. Piano M, Valvassori L, Lozupone E, Pero G, Quilici L, Boccardi E, et al. : FRED Italian Registry: a multicenter experience with the flow re-direction endoluminal device for intracranial aneurysms. J Neurosurg 133 : 174181, 2021

28. Rice $H$, Martínez Galdámez M, Holtmannspötter M, Spelle L, Lagios $K$, Ruggiero $M$, et al. : Periprocedural to 1-year safety and efficacy outcomes with the pipeline embolization device with shield technology for intracranial aneurysms: a prospective, post-market, multi-center study. J Neurointerv Surg 12 : 1107-1112, 2020

29. Tan LA, Keigher KM, Munich SA, Moftakhar R, Lopes DK : Thromboembolic complications with pipeline embolization device placement: impact of procedure time, number of stents and pre-procedure $\mathrm{P} 2 \mathrm{Y} 12$ reaction unit (PRU) value. J Neurointerv Surg 7 : 217-221, 2015

30. Yamada M, Kitahara T, Kurata A, Fujii K, Miyasaka Y : Intracranial vertebral artery dissection with subarachnoid hemorrhage: clinical characteristics and outcomes in conservatively treated patients. J Neurosurg $101: 25-30,2004$

31. Yamaura I, Tani E, Yokota M, Nakano A, Fukami M, Kaba K, et al. : Endovascular treatment of ruptured dissecting aneurysms aimed at occlusion of the dissected site by using Guglielmi detachable coils. J Neurosurg $90: 853-856,1999$

32. Yeung TW, Lai V, Lau HY, Poon WL, Tan CB, Wong YC : Long-term outcome of endovascular reconstruction with the Pipeline embolization device in the management of unruptured dissecting aneurysms of the intracranial vertebral artery. J Neurosurg 116 : 882-887, 2012 